\title{
O ESPÍRITO ASSOCIATIVO E O ENFERMEIRO NO RIO DE JANEIRO
}

\author{
Maria Estela Mourão Heredia ** \\ Herdy de Almeida Vieira *
}

RBEn/08

HEREDIA, M.E.M \& VIEIRA, H.A. - O espírito associativo e o enfermeiro no fio de Janeiro. Rev. Bras. Enf.; Rio de Janeiro, $28: 79-84,1975$.

\section{1 - INTRODUÇÃO}

Verificando a disparidade entre o número de enfermeiros em exercício no Brasil, cerca de 8.000 , com o número de associados da ABEn, pouco mais de 2.000, decidimos estudar como se comporta este problema no Rio de Janeiro.

Também sentimos que seria oportuno incluir nesta pesquisa de opinião dados comparativos sobre o Conselho e o Sindicato pois, se a ABEn, apesar de existir há quarenta e seis anos e ter prestado inúmeros e inestimáveis serviços à classe conta com tão poucos sócios o modo como se sentirão as colegas em relação a essas outras associações é, justificadamente motivo de indagações.

Os objetivos propostos foram:

a) verificar se determinados aspectos da enfermagem como profissão são conhecidos dos enfermeiros

b) conhecer o conceito no qual as enfermeiras têm a ABEn;

c) apurar o conhecimento por parte dos enfermeiros em relação às finalidades da ABEn, Sindicato e Conselho de Enfermagem.

\section{2 - REVISAOO BIBLIOGRAFICA}

A llteratura sobre o assunto é escassa.

RESENDE (1957) lembrava que: "Dar, traduz plenitude no que concretiza suas dådivas, por sermos, no momento, tão crianças ou tão pobres somos ainda gente de pouco dar.

Existe um egoísmo coletivo como existe o individual. A predominância do RECEBER, como valor atribuído à assocíaçāo e como razão para pertencer à ABEn, revela ou esse egoísmo ou a fase ainda infantil da nossa vida associativa.

Aos olhos de muitas enfermeiras, a

- Presidente da ABEn - Seção Guanabara.

Professora da Escola de Auxiliar de Enfermagem do Hospital dos Servidores do Es. tado - IPASE.

** Enfermeira do Centro Cirúrgico do Hospital dos Servidores do Estado - IPASE. 
HEREDIA, M.E.M \& VIEIRA, H.A. - O espírito associativo e o enfermeiro no Rio de Janeiro. Rev. Bras. Enf.; Rio de Janeiro, 28 : 79-84, 1975.

vida associativa NAO TEM VALOR e não merece nem mesmo ser compartilhada.

Aos olhos de outras, a vida associativa constitui um "dever".

A Revista Brasileira de Enfermagem vem publicando anualmente o número de sócios desde a época do trabalho acima referido, apesar de algumas lacunas.

Podemos verificar que os números flutuam de ano a ano mas sem grandes diferenças.

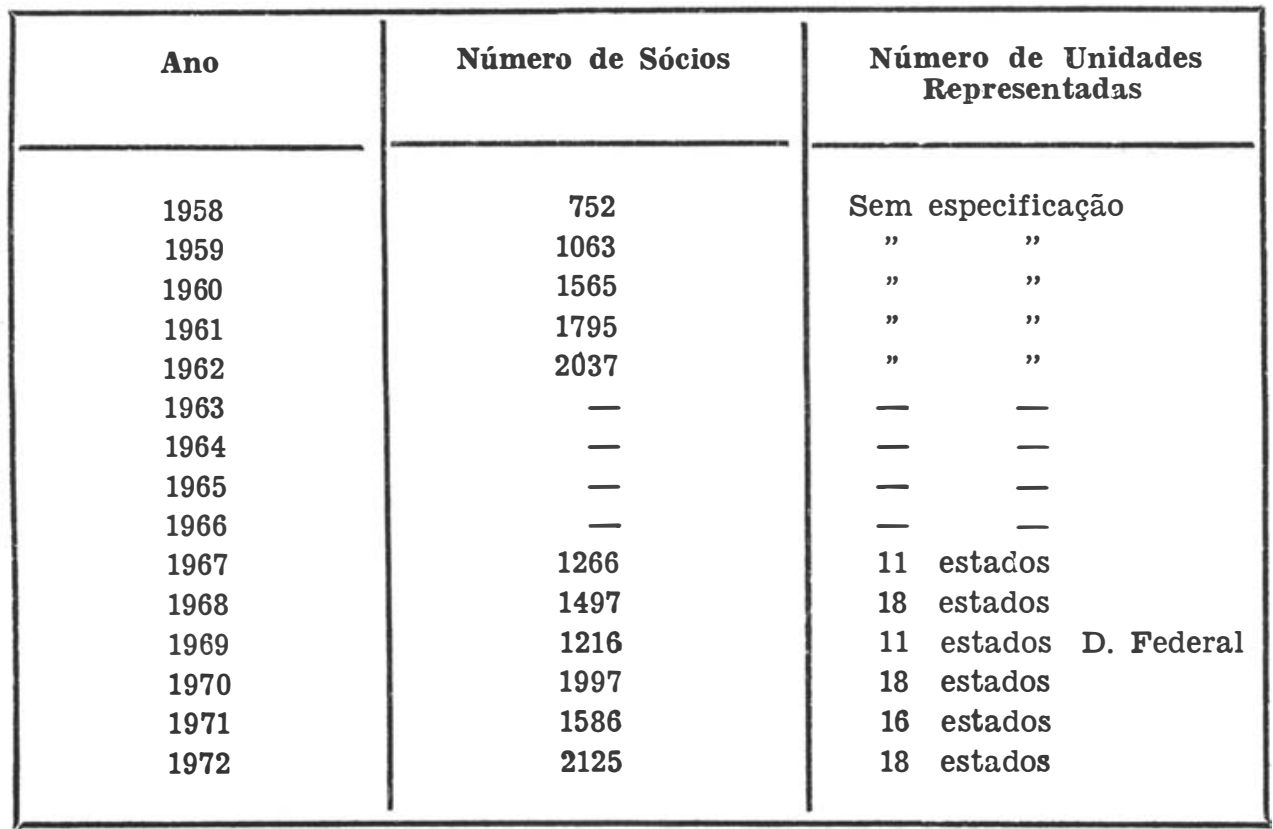

A situação encontrada é essa. Estima-se o número de enfermeiros no Brasil em 10.000 e o número de assoclados, segundo os últimos relatórios da Sra. Presidente da $\mathrm{ABE}$ está em torno de 2482 (1969, 1970, 1972, conforme demonstra o quadro

Constatamos portanto que apenas $25 \%$ são sócias.

\section{MATERIAL E METODO}

3.1 População - enfermeiras em atividade no Rio de Janeiro, representadas por amostragens.

Foram incluídos na amostragem os hospitais que contavam com mais de 15 enfermeiras, ficando por isso excluídas todas as Casas de Saúde e Hospitais particulares.
Vale lembrar que muitas enfermeiras que trabalham em serviços particulares o faz como segunda opção, sendo a primeira o Serviço Público.

Foram Incluidos os Hospitais Estaduais, os do INPS, o do IPASE e do IASEG e os Universitários.

Foi consultado $10 \%$ do número de 
HEREDIA, M.E.M \& VIEIRA, H.A. - O espírito associativo e o enfermeiro no Rio de Janeiro. Rev. Bras. Enf.; Rio de Janeiro, $28: 79-84,1975$.

enfermeiras de cada hospital, Escolas de Enfermagem e Centros de Saúde, incluindo no estudo, o que somar um total de 125 enfermeiras, portanto cerca de $7 \%$ do número presumível existente no Estado.
Escolhemos aleatoriamente o número 6 e seus múltiplos para o sorteio da candidata a participar da amostra. Esse sorteio era feito por mejo de lista fornecida pela Chefe do Serviço de Enfermagem, organizada por ordcm alfabética ou antigüidade.

\section{SERVIÇOS DE ENFERMAGEM REPRESENTADOS NA AMOSTRA E NÚMERO DE RESPONDENTES}

\begin{tabular}{|c|c|c|}
\hline $\begin{array}{c}\text { Serviço de } \\
\text { Enfermagem }\end{array}$ & $\begin{array}{c}\text { Órgão } \\
\text { Matenedor }\end{array}$ & $\begin{array}{c}\text { Número de } \\
\text { Respondentes }\end{array}$ \\
\hline $\begin{array}{l}\text { Centros Médico Sanitários } \\
\text { Hospital Servidores do Estado } \\
\text { Divisão de Saúde Escolar } \\
\text { Hospital Central do IASEG } \\
\text { Hospital de Clínicas } \\
\text { Hospital de Ipanema } \\
\text { Hospital da Lagoa } \\
\text { Hospital Andaraí } \\
\text { Hospital S. Francsico Xavier } \\
\text { Hospital Raphael Paula Souza } \\
\text { Hospital do Câncer } \\
\text { Hospital Souza Aguiar } \\
\text { Hospital Getúlio Vargas } \\
\text { Hospital Carlos Chagas } \\
\text { Hospital Jesus } \\
\text { Hospital Rocha Faria } \\
\text { Instituto de Hematologia } \\
\text { Hospital Aéronautica } \\
\text { Hospital Gafree Guinle } \\
\text { Escola Ana Neri } \\
\text { Escola Alfredo Pinto } \\
\text { Faculdade de Enfermagem }\end{array}$ & $\begin{array}{l}\text { Estado Gb } \\
\text { Ipase } \\
\text { Estado Gb } \\
\text { Estado Gb } \\
\text { Univer. Est. Gb } \\
\text { INPS } \\
\text { INPS } \\
\text { INPS } \\
\text { INPS } \\
\text { M. Saúde } \\
\text { M. Saúde } \\
\text { Estado Gb } \\
\text { Estado Gb } \\
\text { Estado Gb } \\
\text { Estado Gb } \\
\text { Estado Gb } \\
\text { Estado Gb } \\
\text { M. Aéronautica } \\
\text { FEFIEG } \\
\text { UFRJ } \\
\text { FEFIEG } \\
\text { UEG }\end{array}$ & $\begin{array}{r}18 \\
15 \\
10 \\
10 \\
10 \\
8 \\
8 \\
8 \\
3 \\
4 \\
4 \\
4 \\
3 \\
3 \\
2 \\
1 \\
1 \\
3 \\
2 \\
3 \\
3 \\
2\end{array}$ \\
\hline
\end{tabular}

3.2 Instrumento: o questionário foi elaborado tendo em vista os fatores que seriam usados como indicadores do espírito associativo.

Consideramos que seriam pontos positivos: a) ser sócio da ABEn;

b) valorizar a freqüência às reuniões da Associação;

c) ter participado pelo menos em algum Congresso de Enfermagem; 
HEREDIA, M.E.M \& VIEIRA, H.A. - O espírito associativo e o enfermeiro no Rio de Janeiro. Rev. Bras. Enf.; Rio de Janeiro, 28 : 79-84, 1975.

d) Valorizar o poder de reivindicação do grupo;

e) Conhecer a finalidade das três associações: Cultural, Conselhos e Sindicato;

f) Concordar com a existência das três.

As três primeiras questões foram propostas no sentido de se avaliar se o enfermeiro está satisfeito com o que faz e se sente ajustado à profissão.

A quarta questão, assim como a décima oitava e a décima nona, foram elaboridas visando verificar se o enfermeiro está consciente do seu valor como profissional e como acompanha a evolução da classe.

Da quinta à décima sexta procuramos conhecer a opinião de cada um sobre a sua associação de classe. Como no trabalho de Marina de Andrade Resende destacou-se a falta de divulgação da ABEn, incluimos dois quesitos relativos a este ponto.

A décima oitava questão teve a finalidade de verificar a aceitação da carteira da ABEn como condição para admissão em emprego e que já é adotada em alguns hospitais.

O questionário foi testado em um grupo de alunos do $4 .^{\circ}$ ano de uma Escola de Enfermagem sediada no Estado Rio de Janeiro, sendo considerado satisfatório na ocasião, embora, durante a tabulação fossem evidenciadas algumas falhas.

A devolução dos questionários distribuídos às 125 enfermeiras foi integral, para o que muito contribuiu a participação de duas colegas que colaboraram na coleta de dados.

\section{Resultados}

a) Ajustamento à Profissão: Dizemse ajustadas 115 enfermeiras, 92\%: 99-79\% não gostariam de ter escolhido outras profissão e $17-13 \%$ gostariam de ter escolhido outra profissão.

b) Conceito de Profissão Liberal: 20 enfermeiras, $16 \%$ das respondentes consideram profissional liberal aquele que trabalha por conta própria; $1-0,8 \%$ cita - consultório como característica do profissional liberal; 49 respondentes, $39 \%$ entendem como liberal aquele profissional que tem curso universitário; 26-12\% responderam que o curso universitário e a pesquisa caracterizam a profissão liberal; $16-12 \%$ assinalam que a pesquisa é que é característica do profissional liberal.

c) Conhecimento do Status da Profissão: 91 respondentes, $72 \%$ sabem da classificação como profissional liberal no Enquadramento Sindical; 29 enfermeiras, $23 \%$ não sabem; $54-43 \%$ acham que todos os enfermeiros estão integrados no nível universitário; 33-26\% acham que muitos enfermeiros estão integrados e $3-2,4 \%$ respondem que apenas alguns se integraram ao nível superior.

d) Conhecimento das Associações: Conhecem a finalidade de cada uma das três associações 56 enfermeiras $45 \%$; $24-19 \%$ não conhecem e $43-34 \%$ informaram conhecer mais ou menos.

Quanto a conveniência das três existindo simultâneamente (c, Sindicato, o Conselho e a ABEn), 57-46\% concordaram e 14-11\% não concordaram; 35$26 \%$ não sabem e $19-15 \%$ deixaram a resposta em branco.

e) Filiação a ABEn. São sócias da ABEn 66 enfermeiras, $51 \%$; 35-20\% não são sócias e $24-19 \%$ deixaram de ser sócias, perfazendo um total de 59 não sócias.

Verificando o motivo de não se associarem à ABEn, encontrou-se: 15 enfermeiras, $43 \%$ não são sócias por desinteresse e deixaram de ser sócias, pelo mesmo motivo $10-42 \%$; deixaram de ser 
HEREDIA, M.E.M \& VIEIRA, H.A. - O espírito associativo e o enfermeiro no Rio de Janeiro. Rev. Bras. Enf.; Rio de Janeiro, $28: 79-84,1975$.

sócias por decepção, citando como razões o pouco que a ABEn fez pelos enfermeiros, 4 respondentes, $17 \%$. A falta de divulgação alcança apenas 8 enfermeiras, $23 \%$; o problema financeiro é citado por 1 enfermeira, $3 \%$, como razão para não se associar e $3-12 \%$ para deixar de ser sócia. Outros motivos citados para não se associar: falta de tempo, ser sócio de outra associação e mudanças.

f) Importância da ABEn: Em relação as reivindicações 79 enfermeiras, $63 \%$ responderam "não" às possibilidades de sucesso de reivindicações por enfermeiros isolados, enquanto, $17-14 \%$ responderam "sim" e $18-14,5 \%$ as vezes.

Sobre o valor dos trabalhos de Congressos Brasileiros de Enfermagem 100$80 \%$ responderam positivamente e $3,2 \%$ responderam não: $17-14 \%$ não sabem.

A importância de freqüentar reuniões da ABEn é confirmada por $98-78 \%$ : $6 \%$, 8 respondentes, acham que não é importante e 16 enfermeiras, $13 \%$ não sabem.

No trabalho de valorização do "status" 95-76\% atribuem-no à ABEn e 4\%, 5 enfermeiras acham que a ABEn e algumas enfermeiras contribuíram; 19$15 \%$ acham que o trabalho foi feito por algumas enfermeiras isoladas e $2-16 \%$ respondem que ninguém fez nada até hoje.

g) Divulgação das Associações de Classe: Afirmaram que a Escola divulgava a atuação da ABEn 88 enfermeiras, $70 \%$; $24-19 \%$ respondem que as Escolas divulgavam superficialmente. Em 8 instituições $7 \%$, a chefe não divulga.

h) Participação em Congressos de Enfermagem: Nunca participaram de Congressos 53 respondentes; $43 \%$ e apenas $15-12 \%$ compareceram a muitos;
23-19\% participaram de poucos e 31$34 \%$ participaram apenas uma vez.

i) Valor da Carteira da ABEn: 79 respostas, $63 \%$ favoráveis à exigência da carteira de sócia da ABEn para candidatas a emprego e 31-24\%, desnecessária e $8,7 \%$ acharam errada a exigência.

j) Número de Sócias por Escola

- Da Escola Ana Neri responderam 32 enfermeiras, das quais $18-56 \%$ são sócias e 14-43\% não são sócias.

- Da Faculdade de Enfermagem da UEG, 19 são sócias-63\% e 11-37\% não são associadas, do total de 30 enfermeiras que responderam.

- Da Escola Alfredo Pinto aparece com 17 enfermeiras, das quais $5-30 \%$ são sócias e 12-70\% não são.

- Da Escola Luiza de Marilac, 9 respondentes, $4-44 \%$ são sócias e 5-56\% não o são.

- Da Escola de Enfermagem da Cruz Vermelha Brasileira 7 responderam ao questionário sendo $3-43 \%$ sócias e 4$57 \%$ não sócias.

A Escola de Enfermagem da Universidade Federal Fluminente entrou no levantamento com 13 representantes das quais: $9-69 \%$ são sócias e 4-31\% não o são.

As demais pouco representativas.

1) Número de Sócias por Grupo Etário

- De 26 a 39 anos responderam 60 enfermeiras das quais 35 são sócias $58 \%$ e $25-42 \%$ não o são.

- Entre 40 e 49 anos - 48 enfermeiras responderam ao questionário; dessas 20-42\% são sócias e 28-58\% não o são.

- Do grupo etário mais alto - 50 a 66 anos responderam 17 profissionais, sendo 11 sócias $64 \%$ e $6-36 \%$ não são sócias. 
HEREDIA, M.E.M \& VIEIRA, H.A. - O espírito asscciativo e o enfermeiro no Rio de Janeiro. Rev. Bras. Enf.; Rio de Janeiro, $28: 79-84,1975$.

m) Na distribuição percentual, em relação ao número de anos de formada, a moda fica entre as que têm 18 anos de profissão, 12 enfermeiras- $9,6 \%$, se- guindo-se as que tem 21 anos, 9 enfermeiras, $7,2 \%$ e depois as que têm 14 e 15 anos de exercício com 8 enfermeiras cada um, $6,4 \%$.

\section{CONCLUSÕES}

Apesar de a amostra não ser rigorosamente representativa, julgamos poder tirar as seguintes conclusões do estudo:

1 - Há ainda um grande número de enfermeiras que desconhecem as características do profissional liberal e o número que desconhece o enquadramento do enfermeiro como profissional liberal é considerável.

2 - A maior razão para a não filiação e o desinteresse e não a falta de divulgação, conforme relatado em trabalho anterior; vem a seguir a decepção.

3 - As Escolas e os Serviços são núcleos de divulgação das associações; especialmente da ABEn.

4 - Os trabalhos de Congressos têm repercussão mesmo junto às enfermei- ras que não comparecem a Congressos de Enfermagem.

5 - A importância da freqüência às reuniões da ABEn é reconhecida mesmo pelas enfermeiras que não as freqüentam.

6 - mais da metade das enfermeiras não conhece, ou conhece mal as finalidades de cada uma das três associações (Sindicato, Conselho e Associação Cultural).

7 - A maioria das enfermeiras coloca a Associação em primeiro lugar como responsável pela melhoria do "Status" profissional.

8 - Cerca de dois terços das enfermeiras não discordam do processo de exigir carteira da $A B E n$ às candidatas a emprego.

\section{BIBLIOGRAFIA}

1. ABEn - Relatórios das Presidentes à AD referentes aos anos de 1962, 1963, 1967, 1968, 1969, 1970, $1971 \mathrm{e}$ 1972.
2. RESENDE, Marina de Andrade, Significação da Vida Associativa em Enfermagem. Rev. Bras. Enf., 4, 1957: 375-394. 